\title{
Managing Cancer Center During the SARS-COVID-19 Pandemic: Moroccan Experience
}

\author{
Nouama Bouanani ${ }^{1,4 *}$, Mounia Bendari ${ }^{1,4}$, Asmaa Naim ${ }^{2,4 *}$, Maryame Ahnach ${ }^{1,4}$, \\ Safa Darouich ${ }^{1,4}$, Nabil Ismaili3,4, Kamal Doghmi ${ }^{1}$
}

${ }^{1}$ Hematology \& Stem Cell Transplant Department, Blood Transfusion and Cellular Therapy Cheikh Khalifa International University Hospital, Morocco. ${ }^{2}$ Radiotherapy Department, Cheikh Khalifa International University Hospital, Morocco. ${ }^{3}$ Medical Oncology Department, Cheikh Khalifa International University Hospital, Morocco. ${ }^{4}$ Mohammed VI University of Health Sciences (UM6SS), Casablanca, Morocco.

\begin{abstract}
Objective: The principal aim of this work is to describe the different measures taken by three departments involved in treatment of patients followed for cancer during the SARS pandemic COVID-19. Method: A prospective study, using anonymous questionnaire, among the medical and paramedical team of hematology, medical oncology and radiotherapy during the pandemic. Results: The staff nursing was mainly constituted by a paramedical team $(71,5 \%)$, with female predominance at $77,8 \%$, sex ratio $\mathrm{F} / \mathrm{M}=3,5$, the high majority range age of the team was $30-45$ years, living as a couple $(52,4 \%)$. During the Covid pandemic, all our staff used bib, normal bib $(76,2 \%)$, FPP2 (20,6\%) combined bib (FFP2/normal) in 28,6\% with visor in 6,3\%. The duration of using of the same bib was variable, it has been used for $12 \mathrm{~h}$ and more in $52,5 \%$ and during $4 \mathrm{~h}, 6 \mathrm{~h}$ and $8 \mathrm{~h}$ in $12,5 \%, 7,5 \%$ and $27,5 \%$ respectively. For the out work management, more than half of our team return home without confinement to their family or children and only $8 \%$ have been confined on hotel. Our staff expressed a very important professional impact in $87,3 \%$ as well as in their personal lives in $85,7 \%$. Conclusion: The vulnerability of the patients followed for cancer had obliged heath professional in this field to be even more rigorous and more vigilant on protective measures while ensuring continuity of care during the COVID pandemic. Our study illustrates that, despite the staff's efforts of adaptation, the impact in personal and professional lives has been not negligible.
\end{abstract}

Keywords: SARS-Covid-19- neoplasms- hematologic diseases- radiotherapy- oncology

Asian Pac J Cancer Care, 5 (Suppl 1), 219-223

\section{Introduction}

A novel coronavirus (SARS-CoV-2) emerged in Wuhan, China in December 2019. WHO declared a global health emergency on 30 January 2020 [1].

A pandemic coronavirus causes a respiratory illness called COVID-19 disease, which is often severe or life-threatening. Patients with cancer may have compromised immunity due to their disease or its treatment, and early reports suggest cancer is a risk factor for severe COVID-19 disease [2-3].

The COVID-19 pandemic was confirmed to have spread to Morocco on 2 March 2020, when the first case of COVID-19 was confirmed in Casablanca. Morocco
Submission Date: 07/18/2020 Acceptance Date: 08/14/2020

declared a state of medical emergency on 19 March 2020, we reached 7332 cases and 197 Death on May 22, 2020 [4].

\section{Objective}

To describe the different measures taken by the Cancer Center of Casablanca (CCC) department in International University hospital Cheikh khalifa to face and react as quickly as possible to the SARS pandemic COVID-19, ensuring continuity of care for these patients with particular profiles, the secondary goal is to report the various constraints of the medical and paramedical staff

\footnotetext{
*Corresponding Authors:

${ }^{1}$ Dr. Nouama Bouanani, ${ }^{2}$ Dr Asmaa Naim

*The authors had participate equally to this manuscript.

'Hematology \& Stem Cell Transplant Department, Blood Transfusion and Cellular Therapy Cheikh Khalifa International University Hospital, Morocco. ${ }^{2}$ Radiotherapy Department, Cheikh Khalifa International University Hospital, Morocco.

Emails: nouama2009@hotmail.fr, doc.a.naim@gmail.com
} 
during their daily exercise.

\section{Methods}

A prospective study was conducted, with the medical and paramedical team (nurse, computer scientist, secretary, financial direction and major manager) of CCC department during the pandemic. 63 anonymous questionnaires were completed and analyzed.

\section{a) The participants}

All participants were volunteer care providers: Physicians, nurses, other health care workers

\section{b) The questionnaire}

Survey used was established by the principal investigator. Survey content and format were based on prior surveys regarding knowledge.

The questionnaire includes 27 items and used, for the major multiple choice questions, quantitative items regarding management of activity on CCC.

The questionnaire was in French, the form was tested and validated.

\section{c) Statistical analyses}

All survey data was coded and entered into SPSS $16 \cdot 0$ software.

\section{Results}

The staff nursing was mainly constituted by paramedical team $(71,5 \%)$, with female predominance at $77,8 \%$, sex ratio $\mathrm{F} / \mathrm{M}=3,5$, the high majority range age of the team was $30-45$ years, living as a couple $(52,4 \%)$. The majority of our staff had at least 5 years of experience $(57,2 \%)$ and worked only during the day before the pandemic $(65 \%)$. The main characteristics of our staff nursing are summarizing in Table 1.

During the Covid pandemic, all our staff used bib, normal bib (76,2\%), FPP2 (20,6\%) combined bib (FFP2/normal) in $28,6 \%$ with visor in $6,3 \%$. The duration of using of the same bib was variable, it has been used for $12 \mathrm{~h}$ and more in 52,5\% and during $4 \mathrm{~h}, 6 \mathrm{~h}$ and $8 \mathrm{~h}$ in $12,5 \%$, $7,5 \%$ and $27,5 \%$ respectively. We noticed that $79,3 \%$ of our staff didn't attend to the training on the pandemic or on the dressing, and $85,7 \%$ of our staff refused to be systematically screened however the barrier measures were in place in $92 \%$.

Concerning the activity of the service, either consultation and hospitalization were maintained in $65 \%$ of cases and patient visits were limited or forbidden in $82,5 \%$, the distance of 1 meter was respected in $(72,5 \%)$ on the waiting room and our team reported that the cleaning service was more than usual.

For the out work management, $60,3 \%$ used their own mean of transport while $35 \%$ used public transport. More than half of our team, return home to their family or children and only $8 \%$ have been confined on hotels. The shower after work was taken at home in the majority of cases $(95,2 \%)$ and only $4,8 \%$ in hospital $(4,8 \%)$.
Table 1. Summary of the Main Characteristics of the Nursing Staff

\begin{tabular}{|c|c|c|}
\hline Staff Nursing & & \\
\hline & Medical Team & $18(28,5 \%)$ \\
\hline & Auxiliary nurse & $9(14,3 \%)$ \\
\hline & Administrator & $6(9,5 \%)$ \\
\hline & Nurse & $16(25,3 \%)$ \\
\hline & Major nurse & $3(4,8 \%)$ \\
\hline & Medical engineer & $1(1,6 \%)$ \\
\hline & Medical Physic & $3(4,8 \%)$ \\
\hline & Secretary & $4(6,4 \%)$ \\
\hline & Radiotherapy Manipulators & $3(4,8 \%)$ \\
\hline
\end{tabular}

Gender

$\begin{array}{cc}\text { Male } & 14(22,2 \%) \\ \text { Female } & 49(77,8 \%)\end{array}$

Range Age

$\begin{array}{cc}18-29 & 29(46 \%) \\ 30-45 & 33(52,4 \%) \\ >46 & 1(1,6 \%)\end{array}$

Marital Status

$\begin{array}{cl}\text { Single } & 30(47,6 \%) \\ \text { Married } & 33(42,4 \%)\end{array}$

Years of Experience

\begin{tabular}{|c|c|}
\hline $0-5$ years & $27(42,8 \%)$ \\
\hline $5-10$ years & $25(39,7 \%)$ \\
\hline$>10$ years & $11(17,5 \%)$ \\
\hline \multicolumn{2}{|l|}{ Kind of Activity } \\
\hline Covid Alone & $2(3,2 \%)$ \\
\hline Covid and Normal Activity & $19(30,1 \%)$ \\
\hline Normal activity & $42(66,6 \%)$ \\
\hline
\end{tabular}

Our staff expressed a very important professional impact in $87,3 \%$ as well as in their personal lives in $85,7 \%$.

\section{Discussion}

We report the first Moroccan study of managing hematology, radiotherapy and oncology department during the SARS-COVID-19 pandemic.

Our Department of Clinical Hematology recruits and treats patients with blood related disorders. These include blood cancers (Leukemia, Lymphoma, and Multiple Myeloma), disorders associated with low hemoglobin (various types of anemia, including thalassemia and sickle cell anemia) and Stem cell transplantation (creation of the marrow transplant unit at HCK in 2016). The department is also engaged in teaching and training of doctors and medical students and is involved in various research activities.

Regarding the Transplantation activity, we performed 100 autografts in the last 3 years, the service has an autonomy with cell therapy unit and blood bank and blood transfusion center. 
We have 23 rooms: 8 sterile rooms at the transplant unit with controlled air to protect our immunocompromised patients, 15 conventional rooms, medical consultation and day hospital for administration of chemotherapy and targeted therapies.

The staff of the service is made up of a medical team which is compound of 1 senior hematologist, 3 permanent hematologists, 2 trainee doctors, 16 nurses, 9 auxiliary nurses, and 2 major nurse

The management of cancer patients in hematology department during COVID-19 has to be adapted to the new situation, in fact in our CCC, the physicians who manage adult patients with hematologic and oncologic malignancies have rapidly adjusted clinical practices to mitigate the potential risks of COVID-19 to our patients.

As a general security measure, the hospital has set up color-coded signage to separate the covid sector from the sector dedicated to non-covid patients with posters displaying the main health security measures.

Our management and therapeutic decisions followed the local recommendations of the Moroccan society of hematology without limiting ourselves to reporting the recommendations issued by international learned societies (ASH, SFH, EHA, EBMT, SFGM-TC, IFM...) which are sometimes difficult to apply in our context [5-8].

On the organizational level, hematology is considered an essential service in our hospital and should continue its activities even during an epidemic of infectious disease.

The patient expects that his oncological treatment will not be interrupted. To ensure this continuity of services, the following measures have been implemented.

Our department established measures and interventions to maximize the safety of patients requiring a hemopoietic stem cell transplant (HSCT), or high-dose of chemotherapy as well as to protect staff of health providers.

To minimize risks of infection, a strict visitor policy was implemented, special Covid circuit for suspect patients, management of hospital waste, increasing hygiene measures with face masks, hydro alcoholic gel and personal protective equipment, the use of phone calls/WhatsApp messages/telemedicine visits to reduce clinic visits on days when treatment is not scheduled, multidisciplinary consultation meeting by videoconference [5].

For patients we opted for the use of growth factors (G-CSF) to reduce the risk of neutropenia, and extreme confinement between appointments.

Chemotherapy doses can be changed to reduce clinical neutropenia without compromising the curative potential of treatment, patients are isolated in separate rooms for security reasons.

We considered testing patients systematically before high-dose chemotherapy for COVID-19 even in the absence of pulmonary symptoms [8].

Since the newly diagnosed AML is considered emerging from treatment in most cases, intensive induction chemotherapy should always be offered to eligible patients with $7+3$ (cytarabine +daunorubicine). Consolidation / post-remission treatment with high-dose of cytarabine should continue to be offered to patients in complete remission, but we reduced the dose to $1.5 \mathrm{~g} / \mathrm{m}^{2}$ instead of $3 \mathrm{~g} / \mathrm{m}^{2}$.

Autologous stem cell transplants were postponed for all patients, replaced by cryopreservation grafts already mobilized, the decision was made by a multidisciplinary team until the risks associated with the COVID-19 pandemic had passed [9].

COVID-19 had an impact on the availability of labile blood products and the availability of voluntary donors which is due to confinement. This situation should lead us to be more vigilant and economical when prescribing blood products and to use hematopoietic growth factors when possible. We proceeded by a program established in advance to ensure supply of the blood bank by creating awareness of families of aplastic patients, special authorization for blood donation, an apheresis platelet program has been implemented [5-7].

\section{Management of cancer patients in Medical Oncology during COVID-19}

The nursing staff of the service is composed of a medical team consisting of two permanent oncologists, 2 residents and 3 interns.

There is no important change in our practice in medical oncology during coronavirus pandemic. However, we have recommended general measures to limit the contamination of patients and medical staff. The populations at risk are patients with lung cancer who are much more vulnerable to the risk of lung infection. The elderly is also in danger because of their age.

In breast cancer and colon cancer, immunodepression is generally moderate. It is exceptional that we have infections linked to immunodepression. Patients during follow-up and patients treated with endocrine therapy are no more "at risk" than the general population.

\section{Recommendations in medical oncology unit}

1)Advise patients to limit travels and meetings (including family meeting, for example) as much as possible and to respect containment; 2) Systematic taking of the temperature at admission in cancer center and hospitalization units; 3) Make soap and disinfectant gel available to medical staff and patients; 4) Prioritize teleconsultations for follow-up; 5) Avoid accompanying persons in the medical oncology units, except for children or very frail patients; 6) Limit hospitalizations; 7) Postpone certain adjuvant chemotherapies; 8) Be afraid for certain treatments such as targeted therapies (Ex: Everolimus) inducing pulmonary fragility; 9) For patients during concomitant radio-chemotherapy, continue treatment without any delay; 10) Continue adjuvant therapy such as Pertuzumab and Trastuzumab without delay; 11) Postpone chemotherapy by two weeks for frail patients and for patients who have not yet started their adjuvant treatments; 12) Systematic use of Granulocyte Colony Stimulating Factors (GCSF) for cases at risk of developing severe neutropenia; 13) No contraindication for premedication based on short-term corticosteroid therapy [10-14]. 
Management of cancer patients in radiotherapy department during COVID-19

The radiotherapy department has a dedicated scanner for treatment simulation, with three units: External radiotherapy unit with two newest generation of particle accelerators (Clinac ${ }^{\circledR}$ ) 2300iX Varian and a trueBeam Stx $\left.{ }^{\circledR}\right)$, a Dosimetry Unit with contouring and treatment planning consoles and a Brachytherapy unit with a mini operating room and a treatment room equipped with a source projector.

The nursing staff of the service is composed of a medical team consisting of two permanent radiotherapists and 5 temporary radiotherapists as well as 3 physicians on fellowship ( 2 residents and 1 intern) a medical physics team with 3 permanent physicists and a paramedical team with 3 radiotherapy manipulators and a Nurse Major.

Patients with a scheduled appointment were contacted and the need for them to come to the hospital was left to the discretion of their attending physician after a teleconsultation. However, patients who came to the center without a prior appointment were seen on the same day as any paraclinical check-up. The face-to-face multidisciplinary consultation meetings have been suspended and replaced by remote consultation via WhatsApp groups and have been restricted to cases where there are problems with therapeutic indications. When the indication for radiotherapy is chosen, a hypo-fractionated regimen is preferred. Patients undergoing radiotherapy are required to respect the time previously set by the healthcare team in order to reduce the time spent in hospital. In the radiotherapy waiting room, only 4 patients are allowed to stay there, wearing a mask and respecting the recommended distance and making sure that the accompanying persons remain outside the radiotherapy department.

The radiotherapy manipulators wore during Covid pandemic a surgical gown with a surgical mask and are organized so that only one takes control of the treatment console and the other ensures the patient's positioning. A disinfection of the treatment table and the equipment is systematically carried out before each patient passes through.

Weekly monitoring consultations of patients undergoing radiotherapy have been reduced at the request of the patient or following any anomaly noted by the radiotherapy manipulator [15].

\section{Highlights}

- The general measures were respected in our center and we didn't report any case of positive Covid in our patients as well in our staff nursing team during the Covid pandemic.

- We noticed that the duration bib use was inadequate by the majority of our team.

- Health professionals working in cancer treatment are more prone to burnout.

- The Covid pandemic had negative personal and professional impact in our staff nursing probably due to the change in their work pattern.

In conclusion, the SARS-COVID-19 pandemic is a global crisis, but it remains transient, the particularity of the patients followed in onco-hematology and radiotherapy obliges us to be even more rigorous and more vigilant on protective measures while ensuring continuity of care. This SARS-COVID-19 pandemic had a significant impact on our personal and professional lives and especially on our daily medical practice, but thanks to this crisis we were able to accomplish several achievements but it is necessary to maintain and especially to reinforce after the end of the pandemic the hygiene which was put in place to protect the caregiver and the patient.

\section{Acknowledgments}

We thank all the staff of Mohammed VI University of Health Sciences, Casablanca, Morocco specially Mr Saad Zbiri International School of Public Health, Mohammed VI University of Health Sciences (UM6SS), Casablanca, Morocco.

\section{Competing interests}

All authors declare no competing interests.

\section{Authors' contributions}

Bouanani Nouama wrote the letter.

All the authors have read and agreed to the final manuscript.

\section{References}

1. Sohrabi C, Alsafi Z, O’Neill N, Khan M, Kerwan A, Al-Jabir A, Iosifidis C, Agha R. World Health Organization declares global emergency: A review of the 2019 novel coronavirus (COVID-19). International Journal of Surgery. 2020 04;76:71-76. https://doi.org/10.1016/j.ijsu.2020.02.034

2. Weinkove R, McQuilten ZK, Adler J, Agar MR, Blyth E, Cheng AC, Conyers R, Haeusler GM, Hardie C, Jackson C, Lane SW, Middlemiss T, Mollee P, Mulligan SP, Ritchie D, Ruka M, Solomon B, Szer J, Thursky KA, Wood EM, Worth LJ, Yong MK, Slavin MA, Teh BW. Managing haematology and oncology patients during the COVID -19 pandemic: interim consensus guidance. Medical Journal of Australia. 202005 13;212(10):481-489. https://doi. org/10.5694/mja2.50607

3. Willan J, King AJ, Hayes S, Collins GP, Peniket A. Care of haematology patients in a COVID-19 epidemic. British Journal of Haematology. 202003 15;189(2):241-243. https:// doi.org/10.1111/bjh. 16620

4. Ministry of Health of Morocco. Coronavirus disease COVID-19: Situation report. 2020. Accessed 22 May 2020.

5. Recommandations de prise en charge des patients d'hématologie durant la pandémie Covid 19 (Société marocaine d'hématologie 2020).

6. Kattan C, Badreddine H, Rassy E, Kourie HR, Kattan J. The impact of the coronavirus pandemic on the management of cancer patients in Lebanon: a single institutional experience. Future Oncology. 2020 06;16(17):1157-1160. https://doi. org/10.2217/fon-2020-0313

7. COVID-19, Propositions de la Société Française d'Hématologie - 17 Mars 2020.

8. Coronavirus disease Covid-19: EBMT Recommendations update. April 7, 2020.

9. Sahu KK, Siddiqui AD, Cerny J. COVID-19 pandemic 
and impact on hematopoietic stem cell transplantation. Bone Marrow Transplantation. 202005 04; https://doi. org/10.1038/s41409-020-0913-6

10. Trapani D, Marra A, Curigliano G. The experience on coronavirus disease 2019 and cancer from an oncology hub institution in Milan, Lombardy Region. European Journal of Cancer. 2020 06;132:199-206. https://doi.org/10.1016/j. ejca.2020.04.017

11. Banna G, Curioni-Fontecedro A, Friedlaender A, Addeo A. How we treat patients with lung cancer during the SARS-CoV-2 pandemic: primum non nocere. ESMO Open. 2020 04;4(Suppl 2):e000765. https://doi.org/10.1136/ esmoopen-2020-000765

12. Souadka A, Benkabbou A, Al Ahmadi B, Boutayeb S, Majbar MA. Preparing African anticancer centres in the COVID-19 outbreak. The Lancet Oncology. 2020 05;21(5):e237. https:// doi.org/10.1016/s1470-2045(20)30216-3

13. Ismaili N. COVID-19 and gynecological cancers: A Moroccan point-of-view. Radiotherapy and Oncology. 2020 07;148:227228. https://doi.org/10.1016/j.radonc.2020.04.029

14. Sahu KK, Jindal V, Siddiqui AD. Managing COVID-19 in Patients With Cancer: A Double Blow for Oncologists. JCO Oncology Practice. 2020 05;16(5):223-225. https://doi. org/10.1200/op.20.00167

15. Combs SE, Belka C, Niyazi M, Corradini S, Pigorsch S, Wilkens J, Grosu AL, Guckenberger M, Ganswindt U, Bernhardt D. First statement on preparation for the COVID-19 pandemic in large German Speaking Universitybased radiation oncology departments. Radiation Oncology. 202004 07;15(1). https://doi.org/10.1186/s13014-02001527-1

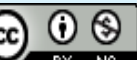

This work is licensed under a Creative Commons AttributionNon Commercial 4.0 International License. 